\title{
Common Beliefs about Bilingualism and Second Language Acquisition
}

\author{
Silva Bratož \\ Faculty of Education, University of Primorska, Slovenia \\ silva.bratoz@pef.upr.si
}

\begin{abstract}
Bilingualism and second language acquisition are today popular topics associated with a number of beliefs and assumptions, which are often unconscious and deeply rooted. Most of these are generally positive, but there are also some negative perceptions. In the present chapter, we discuss some of the most important assumptions related to second language acquisition and the socalled 'bilingual advantage.' In addition, we have tried to identify the principal lines of inquiry in the area of bilingualism and second language acquisition today, such as the research into the effects of early bilingualism on memory loss symptoms in elderly adults with Alzheimer's disease or the beneficial effect of bilingualism on the executive control function. The growing body of literature and related debates shows that the investigation into the benefits of bilingualism and second language acquisition is an expanding and exciting area of research.
\end{abstract}

Keywords: bilingualism, second language acquisition, critical period hypothesis, bilingual advantage

\section{Introduction}

The popularity of topics related to bilingualism and multilingualism has given rise to a number of beliefs and assumptions about the nature of language acquisition and language development. Several popular convictions are today widely held to be true both among teachers and the general public. Both academic journals and mainstream media talk of the 'bilingual advantage' according to which bilinguals enjoy an advantage over monolinguals in several areas, for example in situations which require conflict resolution or multitasking (Paap et al. 2014). The main aim of the present paper is to analyse some of the most common beliefs and assumptions about bilingualism and language acquisition and examine the body of research conducted to prove a particular point.

In reviewing the literature related to the effects and benefits of acquiring and mastering more than one language, it soon becomes clear that the broader field of research includes several aspects which have developed into minor research areas in their own right, such as the body of research on bilin- 
gualism and cognitive decline, bilingualism and early language acquisition, or the existence of a critical period for learning a second language. Considering the complexity and range of aspects studied in the area of bilingualism and language acquisition, the review of literature included in this paper will necessarily be restricted.

In addition, as the concepts discussed in this paper can be analysed from multiple perspectives, the line of inquiry pursued in this study is inevitably limited. For example, an important aspect which is beyond the scope of the present paper is the issue of terminology and definition of the key terms used, including a number of concepts which are today commonly associated with bilingualism and multilingualism, such as plurilingualism, codeswitching, translanguaging and others.

Another important issue which will be discussed only indirectly is the type of bilingualism. In the field of early bilingual development, an important distinction has been made between simultaneous and sequential bilingualism (De Houwer 1999), a distinction which depends on the acquisition age of first exposure to the target languages. The former, also called 'bilingual first language acquisition' (Meisel 1989), refers to the acquisition of two or more languages from birth onwards, while the latter generally refers to situations in which children first acquire their first language and are only then introduced to the second. Children are usually considered sequential bilinguals after the age of three (De Houwer 1999).

The main focus of this paper are beliefs and assumptions, the study of which has been especially widespread in the area of foreign language teaching and learning. Richardson $(1996,103)$ defines beliefs as 'psychologically held understandings, premises, or propositions about the world that are felt to be true.' This is especially important when the beliefs in question are teachers' beliefs. According to Borg (2003) teachers are 'active, thinking decision-makers who make instructional choices by drawing on complex, practically-oriented, personalised, and context-sensitive networks of knowledge, thoughts and beliefs' (p. 81).

Referring to foreign language teachers, Horwitz (1985) points to the importance of making their belief system explicit as this can help them build their professional identities on reliable and tested knowledge rather than on assumptions and erroneous beliefs. Baloh and Bratož (2019) also emphasise that the role of teacher as a reflective practitioner presupposes a critical evaluation of one's own beliefs and assumptions. It is crucial for teachers to be able to identify one's beliefs - a cognitive component of attitudes which play a fundamental role in shaping our behaviour (Žefran 2015). In this re- 
spect, Haukås (2016) and Lundberg (2019) argue that in order to understand the teachers' decision-making in the classroom it is necessary to understand and analyse teachers' beliefs. The overwhelming impact of teachers' beliefs about language learning and acquisition on their instructional choices has triggered a number of studies aimed at identifying teachers' beliefs in different societies and contexts. The main aim of the present paper is to identify and give an overview of some of the most common beliefs about bilingualism and second language acquisition and thus help teachers and researchers make more informed choices and decisions.

\section{Common Beliefs about Bilingualism and Second Language Acquisition} There Is a Critical Period for Acquiring a Second Language

One of the most intriguing questions in the area of foreign language acquisition is whether there is a sensitive period for acquiring a second language. Several studies have tried to prove the connection between the infants' ability to discriminate between phonetic units and second/foreign language acquisition (Tsao et al. 2004; Kuhl 2007). Kuhl (2007) argues that language acquisition requires neural commitment which refers to the process in which children commit the neural networks of the brain to patterns that reflect natural language input. According to this hypothesis, the elements of language which are acquired in infancy are critical as they both support and constrain the future learning of a language. This can be related to the concept of a 'critical' or 'sensitive' period for language acquisition, 'the idea is that the initial coding of native-language patterns eventually interferes with the learning of new patterns (such as those of a foreign language), because they do not conform to the established "mental filter"' (Kuhl 2007, 832).

According to Lenneberg's (1967) critical period hypothesis, the ability to acquire language is biologically linked to age. This means that there is a specific time span to acquire language after which it gradually becomes lateralized in the left hemisphere and language acquisition becomes more difficult. While the hypothesis has often been criticised, some studies did manage to prove that we can indeed talk about a certain critical period in which a language can be acquired at native-speaker level. Kuhl et al. (2005), for example, showed that people who acquired a second language during the early language acquisition stage of development are less sensitive to some explicit grammatical aspects than those who were bilingual from an early period.

Hakuta et al. (2003) tested the critical period hypothesis by trying to identify evidence of discontinuity in the level of English proficiency attained across a large sample of participants in the USA (immigrants with Spanish or Chi- 
nese language backgrounds). In other words, they tried to establish whether there is a cut-off point which signals the end of the critical period. Although their results failed to provide sufficient evidence to prove the existence of discontinuity and thus the critical period hypothesis, they nevertheless presented compelling evidence that there is a correlation between the decline in second language proficiency and increase in age.

In a study in which they used applied functional magnetic resonance imaging (fMRI), Kim et al. (1997) tried to determine how different languages are represented in the human brain. They analysed the language sensitive regions (Broca area) in the brain connected to the native language and other languages and concluded that they are represented in different frontal cortical areas depending on the language acquisition stage of development.

Another relevant body of studies focused on the infants' ability to recognize the differences between distinctive phonetic units or phonemes (Kuhl et al. 2003; Tsao et al. 2004; Kuhl 2007). While after a certain age people are not able to discriminate among phonetic units of a non-native language, infants are capable of discriminating among practically all non-identical sounds or phonemes. It is interesting to note at this point that while all the languages in the world contain around 600 consonants and 200 vowels, an individual language uses only about 40 distinctive phonemes responsible for changing the meaning of the word (Kuhl 2007).

Unlike adults, infants are capable of discerning differences among phonetic units both of their native language and foreign languages. Kuhl et al. (2003) have shown that the ability to discriminate among the phonemes of a second language declines considerably in the period between 6 and 12 months of age. Their study was aimed at identifying the necessary and sufficient conditions for the reversal of the decline in the perception of foreign language sounds. In one of the experiments, for example, they carried out several laboratory sessions in which they exposed 9-month old American infants to native Mandarin Chinese speakers. The results of the study indicated that compared to the control group, exposure to Mandarin reversed the decline in the perception of foreign phonemes in the experimental group.

\section{It Is Better If We Start Learning a Foreign Language Young}

The critical period hypothesis is also at the centre of discussions in the area of foreign language learning. There is today a widely held belief that if we start learning a foreign language young, we will end up as better speakers of that language (Brewster et al. 2002). The question of age is reflected in the worldwide trend of teaching a foreign language to ever younger children. A 
standard argument claims that starting early is especially important for acquiring a natural pronunciation and native-like accent.

Although several studies have been carried out trying to prove the advantages of an early start, it is impossible to give a conclusively positive answer to the question of appropriate age for language learning (Pinter 2011; Lightbown and Spada 2006; Brewster et al. 2002). Rather than a definite answer, there is a general consensus among researchers that we can speak of benefits for different age groups. One of the most important benefits of starting young is that children are more sensitive to the sound and rhythm of the foreign language which means that they are more likely to develop good pronunciation. They are generally less inhibited than older learners and have lower anxiety levels. Pinter $(2006,29)$ also argues that by starting early, they ultimately dedicate more time to language learning than those who start later in life.

On the other mean, there are several advantages of starting to learn a foreign language later in life, in puberty or adulthood. For one, older learners are able to understand and analyse the rules of the new language which allows them to use more efficient strategies for learning it. They can rely on a much more developed conceptual knowledge network and superior cognitive abilities compared to younger learners (Birdsong 1992). Most importantly, however, they usually have a clear sense of why they are learning the foreign language (Pinter 2006, 29).

\section{Bilinguals Control a Smaller Vocabulary in Each Language than Monolinguals}

A systematic account of research related to the claim that bilingual children control a smaller vocabulary than their monolingual peers can be found in the article 'Bilingualism: The good, the Bad and the Indifferent' by Ellen Bialystok (2009). The results of a number of studies have shown that it is indeed true that bilinguals control a smaller vocabulary in each language than people who are monolingual. These findings are based on research which involved people carrying out a variety of tasks aimed at testing their vocabulary size, access to vocabulary and retrieval of lexical items. In these tasks, bilinguals' performance was significantly poorer than that of their monolingual peers. For example, they were slower in picture naming, in verbal frequency tasks, they had more 'tip-of-the-tongue' experiences, identified words through noise less efficiently and experienced more interference in lexical choices. One possible explanation for the differences between bilinguals and monolinguals in vocabulary control can be found in the conflict 
created by the competition of the two languages which is present in bilinguals but not their monolingual peers.

On the other hand, the conflict and competition between the two languages also means that bilingual language production needs a special mechanism to manage and control attention to the target language, for example by inhibiting the interfering lexical option. This means that bilingual people may be equipped with a more efficient function of executive control, which involves processes, such as inhibition, tasks switching, and updating information in working memory. A number of studies (c.f. Bialystok 2009) based on various cognitive tasks have reported that bilingualism does indeed have a beneficial effect on the executive control function (EF). One of the findings of these studies is, for instance, that bilingual children develop the ability to solve problems that contain conflicting or misleading information at an earlier stage than their monolingual peers. Although it is still not clear which mechanisms and processes lie behind the different ways in which bilinguals and monolinguals process verbal information, the research shows that tasks based primarily on verbal control are performed better by monolinguals while tasks involving executive control are performed better by bilinguals.

A related study was carried out by Hoff et al. (2012) aimed at comparing the language development of bilingual and monolingual children. The results of the study showed that in single language comparisons, bilingually developing children showed a significantly lower performance in items measuring vocabulary and grammar. However, on a measure of total vocabulary, the performance of the two groups was not significantly different. In this respect, the authors (Hoff et al. 2012) point to the importance of the relative amount of input in one or more languages.

On the other hand, in a study aimed at analysing the advantage of bilinguals in executive processing, Paap et al. (2014) argue that there is no conclusive evidence for the existence of such an advantage and point to considerable bias on the part of researchers to privilege positive results over null results. According to the authors (Paap et al. 2014, 634), 'ideal bilinguals who acquire both languages early and live in language communities that speak the same two languages are not likely candidates for enhanced executive functions.' As discussed by Paap and Greenberg (2013), the problem lies in the fact that most of the studies which have tried to show the bilingual advantage in EF have used only one task and one indicator for each element of the executive function while studies which used multiple tasks have not managed to prove the bilingual advantage. 


\section{Bilingualism and Plurilingualism Delay Alzheimer's Disease}

This claim is based on the exciting discovery that some activities can be used to exercise the brain and that an increased 'brain fitness' can work as protection against cognitive decline. A number of studies have recently discussed the effect of early bilingualism on memory loss symptoms in elderly adults with Alzheimer's disease and other forms of dementia (Bialystok et al. 2007; Chertkow et al. 2010; Klein et al. 2016). According to a study carried out by Bialystok et al. (2007) focused on multilingual elderly patients, bilinguals showed symptoms of dementia 4 years later than monolinguals which might point to an increased cognitive reserve of bilingual individuals compared to their monolingual peers.

Another study, carried out by Chertkow et al. (2010), reported no significant advantage in bilinguals overall as regarded the age Alzheimer's disease was diagnosed. However, the study revealed another interesting result, i.e. that the delaying effect of bilingualism was significant in a group of immigrants and non-immigrants whose first language was French but not in a group of non-immigrants whose first language was English.

In a study in which they compared the mean number of languages spoken by the inhabitants of 93 countries and the incidence of Alzheimer's disease in the country's population, Klein et al. (2016) found a significant decline in the incidence of Alzheimer's disease consistent with an increase in population multilingualism. However, the authors recommend viewing the results obtained with caution since there might be other 'hidden' factors, such as the socioeconomic status of the population, which may influence the positive evidence for the findings in question. They also point out that further research with more comprehensive data is necessary to assess the effect of multilingualism on cognitive decline.

\section{Bilinguals Confuse Their Languages}

Bilingual or plurilingual speakers often alternate or switch between two or more languages or language varieties or codes during the same conversation. We call this kind of mixing which is characteristic of bilingual or plurilingual communication code-mixing or code-switching. However, as Ibrahim (2015) points out, this kind of alternation does not happen haphazardly: 'it is rule-governed and embedded in the syntactical and morphological structure of the languages used. The base language - the main language chosen for communication -accommodates the guest language at specific changeover points in a sentence or in a word. This allows multilingual communication to flow.' Code-switching is influenced by several factors, such as 
the need to stress a certain point or adapt the language to the audience. Sometimes a word or expression from a different language is simply more appropriate or suitable for the given subject. It is especially important to note that code-switching is used by speakers who are fluent in the two or more languages and intentionally alternate between them, unlike language learners who, for example, use a word from their native language to fill a lexical gap in their knowledge of a target language.

In bilingual or multilingual social contexts, engaging in code-switching often reflects the speakers' desire to associate themselves with identities related to the languages involved (Myers-Scotton 1993; 1997). Besides the obvious cases of filling the lexical gap, the motivation for code-switching is in being perceived as a cooperative person who takes into account the different contexts and backgrounds of the speakers in the communicative situation. As Calteaux $(1994,120)$ points out in her sociolinguistic analysis of Black urban speech communities in South Africa:

An important function of Mixed language is therefore that it forces you to accommodate to other people, to be patient, to not be stubborn, to try your best to make it easier for the other person to understand you, because you do not always know what language they speak.

\section{Bilingualism Causes Delay in Children's Language Development}

According to popular belief, hearing two different languages in early childhood might lead to language acquisition problems. Children who are exposed to two or more languages might be confused and show language delays or even disorders. However, no empirical evidence linking language delays to bilingualism has been found so far. According to De Houwer (2009), there is no difference in the language development between monolingual and bilingual children. On the contrary, bilingual children might actually have an advantage over monolingual peers as they 'need to pay extra attention to what speakers intend to say, since the variation in the different words they hear is so much greater in a bilingual setting' De Houwer $(2009,241)$.

\section{Bilinguals Think in Two Different Languages}

Another avenue of research related to bilingualism focuses on the understanding of the cognitive processes activated by bilinguals when they use different languages. A common question is whether bilinguals also think (or dream) in two different languages. Grosjean (2013) points out that bilinguals can use different modes depending on who they are interacting with 
- when communicating with monolinguals they will be in a monolingual mode, while they will switch to the bilingual mode in interaction with bilinguals. However, does the fact that they are in a 'bilingual mode' also mean that they think in two different languages? $\mathrm{Li}(2018,18)$ argues that 'it is hard to imagine that they (bilinguals) shift their frame of mind so frequently in one conversational episode let alone one utterance.' Rather than assuming that we think in the language we speak a more likely explanation would be that we think in a different form of language, our own idiolect, which again is different from the language-of-thought. In short, 'we do not think in Arabic, Chinese, English, Russian, or Spanish; we think beyond the artificial boundaries of named languages in the language-of-thought' (Li 2018, 19).

The idea that bilingual speakers think in two different languages is also connected with one specific view of bilingualism according to which a bilingual person has two separate and distinctive language competences. As Grosjean $(1989,4)$ points out, this view implies that a bilingual person is practically 'two monolinguals in one person,' a perspective which is associated with an extremely monolingual view of bilingualism.

\section{Children Just 'Pick' up a New Language}

Another popular conviction is that it is really easy for children to learn a new language, that children just simply 'pick' a language 'up' effortlessly and naturally. Looking at children learning and acquiring a foreign language may indeed give us the impression that they are like sponges, soaking up new languages like blotting paper. However, learning a foreign language is far from simple, it involves developing different communication skills and competences, such as taking part in an interaction or expressing one's opinion. And before children can become competent speakers of a foreign language, they have to be exposed to a variety of different contexts, but they also need a lot of life experience in order to grasp the complexity of language (De Houwer 1999).

Learning a foreign language is a complex process which involves a range of cognitive practices, such as deduction and memorization, but also active practice and, above all, motivation. In order to develop effective communicative competences in two or more languages, a child needs a strong supportive environment. In this respect, Clarke (2009) stresses the importance of supportive and predictable environments in which children can develop positive relationships with parents, teaching professionals, and their peers. In addition, a stimulating and supportive language environment will include language which is contextualised and supported by visual materials. It will 
enable learners to participate in rich language interactions in which both the first and the home language are encouraged.

\section{We Can Learn a Foreign Language Better When Interacting with Other People}

As indicated by contemporary theories of learning (Vygotsky 2012; Bruner 1983), social interaction plays a crucial role in language acquisition while social isolation may have seriously negative effects on speech and language development. In this respect, Bruner $(1983,39)$ contends that 'if there is a Language Acquisition Device, the input to it is not a shower of spoken language but a highly interactive affair shaped, as we have already noted, by some sort of an adult Language Acquisition Support System.' The findings of several studies (Kuhl 2007) suggest that infants who have been exposed to a second language in a specific social context acquire foreign sounds much more efficiently and long-term compared to infants who have been exposed to the language only aurally and visually (for example through a TV screen).

The question is in what way social interaction influences early speech development. Kuhl (2007) proposes two mechanisms. The first involves the infants' motivation, which can be analysed by examining the infants' attention and arousal. The study reported by the author (Kuhl 2007) showed that the attention of an infant was considerably higher in response to a live person than an inanimate source. The second mechanism takes into account the information content of the setting in which the infant is placed and includes other elements besides the language input, such as different objects and the speaker's intention and gaze. In this context, gaze following is seen as an important predictor of receptive vocabulary. The results suggest that social signals foster learning as they enable a referential setting rich with information. In this respect, Tomasello (1999) argues that 'language does not create new cognitive processes out of nothing, of course, but when children interact with other persons intersubjectively and adopt their communicative conventions, this social process creates a new form of cognitive representation - one that has no counterpart in other animal species' (Tomasello 1999, 213).

In a study in which two- and three-year-old children were exposed to several foreign language situations created by two speakers in two languages (English and Italian), Sila and Bratož (2019) concluded that even short-term exposures may have a positive impact on the children's perception of different languages and that children clearly associate a particular language with the speaker of that language. 


\section{Most People in the World are Monolingual}

Finally, it is often believed that bilingualism or plurilingualism is a much rarer phenomenon than monolingualism. According to Grosjean (2010), most people think that bilingual people are only found in some countries, such as Canada and Switzerland and that in order to be classified as 'bilingual,' you need to show equal speaking and writing fluency and native-like pronunciation in the languages you speak. The reality seems to be quite different. According to some estimates, bilingual or plurilingual people account for at least half of the world's population and the proficiency of bilingual people in the languages they speak is rarely equal. But how many bilingual or plurilingual people are there in the world? In order to answer this question, we would first have to agree on a common understanding of who is actually bilingual. Are you bilingual if you know two languages, use two languages or if you spoke two languages when you were a child? In addition, to be able to count the number of languages spoken by an individual, we would have to agree on what counts as a language in the first place.

However, we do have some useful data available for some parts of the world. According to the Eurobarometer Report Europeans and their Languages (European Commission 2012), just over half of Europeans (54\%) are able to hold a conversation in at least one additional language, while a quarter $(25 \%)$ reported being able to speak at least two additional languages. And as stated by the Eurostat report in $2016,24.8 \%$ of working-age adults in the $\mathrm{EU}$, who knew at least one foreign language, reported that they knew their best-known foreign language at a proficient level.

In North America, the estimated bilingual population is 35\%, while in the 2000 census in the United States $18 \%$ of the people reported using another language. Furthermore, as Grosjean (2010) points out, while the statistics for Asian and African countries are scarce, we can safely assume that the percentages for North America and Europe would undoubtedly be surpassed in these areas.

\section{Conclusion}

Bilingualism and second language acquisition are today extremely popular topics and this popularity has inevitably generated a number of interesting myths and assumptions, such as the belief that children absorb new languages like sponges or that bilingualism delays a child's language development. As we have seen above, while most of these myths are overwhelmingly positive, there are also some negative perceptions. Both perspectives can be related to often deeply rooted beliefs and assumptions. 
In addition to popular convictions, we can today witness a growing body of studies and reports which attempt to prove the 'bilingual advantage.' In the present chapter, we have tried to identify some of the most important lines of inquiry in the area of bilingualism and language acquisition today. One of the most exciting lines of research concerns the effects of early bilingualism on memory loss symptoms in elderly adults with Alzheimer's disease and other forms of dementia. As we have seen, the research in this area has produced some very encouraging results but has also pointed to several aspects which need to be further investigated. Another significant body of studies has tried to prove the beneficial effect of bilingualism on the executive control function. Despite some positive findings in this area, however, some authors point to methodological issues which put the evidence presented in question.

Finally, one of the aims of the present chapter was to show that there is a substantial body of literature aimed at promoting the benefits of bilingualism and early second language acquisition. This suggests that there is a growing interest both among the general public and the scientific community in the topics discussed above.

\section{References}

Baloh, Barbara, and Silva Bratož. 2019. 'Refleksija vloge učitelja v čezmejnem prostoru.' Razprave in gradivo: revija za narodnostna vprašanja 83:5-19.

Bialystok, Ellen. 2009. 'Bilingualism: The Good, the Bad, and the Indifferent.' Bilingualism: Language and Cognition 12 (1): 3-11.

Bialystok, Ellen, Fergus I. M. Craik, and Morris Freedman. 2007. 'Bilingualism as a Protection Against the Onset of Symptoms of Dementia.' Neuropsychologia 45 (2): 459-64.

Birdsong, David. 1992. 'Ultimate Attainment in Second Language Acquisition.' Language 68 (4): 706-55.

Borg, Simon. 2003. 'Teacher Cognition in Language Teaching: A Review of Research on What Language Teachers Think, Know, Believe, and Do.' Language Teaching 36 (2): 81-109.

Brewster, Jean, Gail Ellis, and Denis Girard. 2002. The Primary English Teacher's Guide. Harlow: Longman.

Bruner, Jerome S. 1983. 'Education as Social Invention.' Journal of Social Issues 39 (4): 129-41.

Calteaux, Karen Vera. 1994. 'A Sociolinguistic Analysis of a Multilingual Community.' Doctoral dissertation, University of Johannesburg.

Chertkow, Howard, Victor Whitehead, Natalie Phillips, Christina Wolfson, Julie Atherton, and Howard Bergman. 2010. 'Multilingualism (But Not Always Bilingualism) Delays the Onset of Alzheimer Disease: Evidence from a Bilingual Community.' Alzheimer Disease \& Associated Disorders 24 (2): 118-25. 
Clarke, Priscilla M. 2009. Supporting Children Learning English as a Second Language in the Early Years (Birth to Six Years). Victoria: Victorian Curriculum and Assessment Authority.

De Houwer, Annick. 1999. 'Environmental Factors in Early Bilingual Development: The Role of Parental Beliefs and Attitudes.' In Bilingualism and Migration, edited by Guus Extra and Ludo Verhoeven, 75-96. The Hague: Mouton de Gruyter.

De Houwer, Annick. 2009. Bilingual First Language Acquisition. Bristol: Multilingual Matters.

European Commission. 2012. Europeans and Their Languages. Special Eurobarometer 243. Brussels: European Commission.

Grosjean, François. 1989. 'Neurolinguists, Beware! The Bilingual Is Not Two Monolinguals in One Person.' Brain and Language 36 (1): 3-15.

Grosjean, François. 2010. Bilingual Life and Reality. Cambridge: Harvard University Press.

- 2013. 'Bilingual and Monolingual Language Modes.' In The Encyclopedia of Applied Linguistics, edited by Carol Chapelle, 489-93. Hoboken, MA: Blackwell.

Haukås, Åsta. 2016. 'Teachers' Beliefs about Multilingualism and a Multilingual Pedagogical Approach.' International Journal of Multilingualism 13 (1): 1-18.

Hakuta, Kenji, Ellen Bialystok, and Edward Wiley. 2003. 'Critical Evidence: A Test of the Critical-Period Hypothesis for Second-Language Acquisition.' Psychological Science 14 (1): 31-38.

Hoff, Erika, Cynthia Core, Silvia Place, Rosario Rumiche, Melissa Señor, and Marisol Parra. 2012. 'Dual Language Exposure and Early Bilingual Development.' Journal of Child Language 39 (1): 1-27.

Horwitz, Elaine K. 1985. 'Using Student Beliefs about Language Learning and Teaching in the Foreign Language Methods Course.' Foreign Language Annals 18 (4): 333-40.

Ibrahim, Nayr. 2015. 'A Few Myths about Speakers of Multiple Languages.' https://www.britishcouncil.org/voices-magazine/few-myths-about -speakers-multiple-languages

Kim, Karl H., Norman R. Relkin, Kyoung-Min Lee, and Joy Hirsch. 1997. 'Distinct Cortical Areas Associated with Native and Second Languages.' Nature 388 (6638): 171-74.

Klein, Raymond M., Christie, John, and Mikael Parkvall. 2016. 'Does Multilingualism Affect the Incidence of Alzheimer's Disease? A Worldwide Analysis by Country.' SSM-population Health 2:463-67.

Kuhl, Patricia K. 2007. 'Is Speech Learning “Gated" by the Social Brain?' Developmental Science 10 (1): 110-20.

Kuhl, Patricia. K., Barbara T. Conboy, Denise Padden, Tobey Nelson, and Jessica Pruitt. 2005. 'Early Speech Perception and Later Language Development: 
Implications for the Critical Period.' Language Learning and Development 1 (3-4): 237-64.

Kuhl, Patricia K., Feng-Ming Tsao, and Huei-Mei Liu. 2003. 'Foreign-Language Experience in Infancy: Effects of Short-Term Exposure and Social Interaction on Phonetic Learning.' Proceedings of the National Academy of Sciences 100 (15): 9096-101.

Lenneberg, Eric H. 1967. Biological Foundations of Language. New York: Wiley.

Li, Wei. 2018. 'Translanguaging as a Practical Theory of Language.' Applied Linguistics 39 (1): 9-30.

Lightbown, Patsy M., and Nina Spada. 2006. How Languages Are Learned. Oxford: Oxford University Press.

Lundberg, Adrian. 2019. 'Teachers' Beliefs about Multilingualism: Findings from Q Method Research.' Current Issues in Language Planning 20 (3): 266-83.

Meisel, Jürgen M. 1989. 'Early Differentiation of Languages in Bilingual Children.' In The Bilingualism Reader, edited by Li Wei, 322-47. London: Routledge.

Myers-Scotton, Carol. 1993. Social Motivations for Code-Switching: Evidence from Africa. Oxford: Clarendon Press.

- 1997. 'Code-Switching.' In The Handbook of Sociolinguistics, edited by Florian Coulmas, 217-237. Oxford: Blackwell.

Paap, Kenneth R., and Zachary I. Greenberg. 2013. 'There Is No Coherent Evidence for a Bilingual Advantage in Executive Processing.' Cognitive Psychology 66 (2): 232-58.

Paap, Kenneth R., Hunter A. Johnson, and Oliver Sawi. 2014. 'Are Bilingual Advantages Dependent upon Specific Tasks or Specific Bilingual Experiences?' Journal of Cognitive Psychology 26 (6): 615-39.

Pinter, Annamaria. 2006. Teaching Young Language Learners. Oxford: Oxford University Press.

- 2011. Children Learning Second Languages. London: Palgrave Macmillan.

Richardson, Virginia. 1996. 'The Role of Attitudes and Beliefs in Learning to Teach.' In Handbook of Research on Teacher Education, edited by John Sikula, 102-19. New York: Macmillan.

Sila, Anita, and Silva Bratož. 2019. 'Kako otroci prvega starostnega obdobja zaznavajo različne jezike?' In Vzgoja in izobraževanje predšolskih otrok prvega starostnega obdobja, edited by Sonja Čotar Konrad, Bogdana Borota, Sonja Rutar, Karmen Drljić, and Giuliana Jelovčan, 277-94. Koper: Založba Univerze na Primorskem.

Tomasello, Michael. 2009. The Cultural Origins of Human Cognition. Cambridge, MA: Harvard University Press.

Tsao, Feng-Ming, Huei-Mei Liu, and Patricia K. Kuhl. 2004. 'Speech Perception in Infancy Predicts Language Development in the Second Year of Life: A Longitudinal Study.' Child Development 75 (4): 1067-84. 
Vygotsky, Lev Semenovich. 1997. Problems of the Theory and History of Psychology. New York: Plenum Press.

Žefran, Mojca. 2015. 'Students' Attitudes towards Their EFL Lessons and Teachers: Their Retrospective Study.' The Journal of Elementary Education 8 (1-2): 167-81. 